\title{
Factors Affecting Conception Rates Following Artificial Insemination or Embryo Transfer in Lactating Holstein Cows
}

\author{
D. G. B. Demetrio, ${ }^{*}$ R. M. Santos, † C. G. B. Demetrio,‡ and J. L. M. Vasconcelos ${ }^{\star 1}$ \\ *Departamento de Produção Animal, FMVZ, UNESP, Botucatu, São Paulo, Brazil \\ †UFU, Universidade Federal de Uberlândia, Minas Gerais, Brazil \\ ‡Departamento de Ciencias Exatas, ESALQ, USP, Piracicaba, São Paulo, Brazil
}

\begin{abstract}
The objective of this study was to evaluate the factors that may affect conception rates $(\mathrm{CR})$ following artificial insemination (AI) or embryo transfer (ET) in lactating Holstein cows. Estrous cycling cows producing $33.1 \pm$ $7.2 \mathrm{~kg}$ of milk/d received $\mathrm{PGF}_{2 \alpha}$ injections and were assigned randomly to 1 of 2 groups (AI or ET). Cows detected in estrus $(\mathrm{n}=387)$ between 48 and $96 \mathrm{~h}$ after the $\mathrm{PGF}_{2 \alpha}$ injection received $\mathrm{AI}(\mathrm{n}=227) 12 \mathrm{~h}$ after detection of estrus or ET $(n=160) 6$ to 8 d later ( 1 fresh embryo, grade 1 or 2 , produced from nonlactating cows). Pregnancy was diagnosed at 28 and $42 \mathrm{~d}$ after estrus, and embryonic loss occurred when a cow was pregnant on d 28 but not pregnant on d 42 . Ovulation, conception, and embryonic loss were analyzed by a logistic model to evaluate the effects of covariates [days in milk (DIM), milk yield, body temperature (BT) at d 7 and 14 post$\mathrm{AI}$, and serum concentration of progesterone (P4) at d 7 and 14 post-AI] on the probability of success. The first analysis included all cows that were detected in estrus. The CR of AI and ET were different on d 28 (AI, 32.6\% vs. ET, $49.4 \%)$ and $42(\mathrm{AI}, 29.1 \%$ vs. ET, $38.8 \%)$ and were negatively influenced by high BT (d 7) and DIM. The second analysis included only cows with a corpus luteum on d 7. Ovulation rate was $84.8 \%$ and was only negatively affected by DIM. Conception rates of AI and ET were different on d 28 (AI, 37.9\% vs. ET, 59.4\%) and 42 (AI, $33.8 \%$ vs. ET, $46.6 \%$ ) and were negatively influenced by high BT (d 7). The third analysis included only ovulating cows that were $7 \mathrm{~d}$ postestrus. Conception rates of $\mathrm{AI}$ and $\mathrm{ET}$ were different on $\mathrm{d} 28$ (AI, 37.5\% vs. ET, $63.2 \%)$ and $42(\mathrm{AI}, 31.7 \%$ vs. ET, $51.7 \%)$ and were negatively influenced by high BT (d 7). There was a positive effect of serum concentration of $\mathrm{P} 4$ and a negative effect of milk production on the probability of conception for the AI group but not for the ET group. The fourth analysis was embryonic loss (AI, 10.8\% vs.
\end{abstract}

Received March 23, 2007.

Accepted July 31, 2007.

${ }^{1}$ Corresponding author: vasconcelos@fca.unesp.br
ET, 21.5\%). The transfer of fresh embryos is an important tool to increase the probability of conception of lactating Holstein cows because it can bypass the negative effects of milk production and low $\mathrm{P} 4$ on the early embryo. The superiority of ET vs. AI is more evident in high-producing cows. High BT measured on d 7 had a negative effect on CR and embryonic retention. Key words: embryo transfer, artificial insemination, conception rate, dairy cow

\section{INTRODUCTION}

Reproductive efficiency in lactating dairy cows has declined and has been associated with the increase in average milk production (Lucy, 2001; Washburn et al., 2002). Lactating dairy cows have increased metabolism because of milk production that decreases the ability to dissipate heat (Kadzere et al., 2002). The negative effects of high milk production on oocyte quality, fertilization, and early embryonic development are exacerbated by heat stress (Hansen and Arechiga, 1999). Oocytes and embryos at early stages are extremely sensitive to heat stress. High environmental temperatures reduce the rate at which embryos progress during the development period (Ealy et al., 1993). Embryos 3 d after conception and older are less sensitive to heat stress (Ealy et al., 1993; Hansen and Arechiga, 1999). Sartori et al. (2002) reported that lactating cows had a greater increase in body temperature (BT) in response to an increase in environmental temperature than heifers and that the reproductive performance of heifers did not change during the summer. They recovered embryos and oocytes from Holstein cows and heifers during the summer, $6 \mathrm{~d}$ after observation of estrus, and verified that the fertilization rate was greater in heifers than in lactating cows. The percentage of good quality embryos was also greater in heifers than in lactating cows. Differences in fertilization rate between lactating and nonlactating cows in winter were not found but the percentage of good quality embryos was greater in nonlactating cows than in lactating cows. 
Progesterone controls LH pulsatility (Bergfeld et al., 1996), follicular dynamics (Stock and Fortune, 1993), the uterine environment (Thatcher et al., 2001; Green et al., 2005), and embryonic development (Mann and Lamming, 2001). High-producing dairy cows have lower plasma concentrations of progesterone (P4; Vasconcelos et al., 1999), perhaps because of the increase in DMI, which increases liver blood flow and the metabolic clearance rate of P4 (Sangsritavong et al., 2002; Vasconcelos et al., 2003). There is a positive correlation between DMI and milk production in lactating dairy cows (Harrison et al., 1990) and an inverse relationship between feed intake and peripheral plasma concentrations of P4 (Vasconcelos et al., 2003). Stronge et al. (2005) demonstrated that low P4 between d 5 and 7 after AI was associated with low fertility in dairy cows. Mann et al. (2006) observed that P4 supplementation $5 \mathrm{~d}$ after AI resulted in better embryonic development. These data indicate that the concentration of $\mathrm{P} 4$ is important during the first days after insemination and it may be one of the factors that determines the success or failure of pregnancy in lactating dairy cows.

Embryo transfer has been used as a method to attenuate some detrimental effects of heat stress on fertility (Putney et al., 1989; Drost et al., 1999). Putney et al. (1989) transferred fresh embryos produced in heifers to lactating Holstein cows in the summer and observed that there was an increase in conception after embryo transfer (ET) relative to AI when pregnancy was diagnosed within 45 d. Drost et al. (1999) compared frozenthawed embryos produced in vivo with AI during the summer. Ovulation was determined by the presence of CL on cows that received an embryo and by concentrations of $\mathrm{P} 4$ on $\mathrm{d} 7$ in AI cows. There was an increase in conception rate $(\mathbf{C R})$ when embryos were used. No differences were detected by Sartori et al. (2006) for CR after AI or after ET.

The hypothesis for this study was that the transfer of fresh embryos would increase the CR of lactating Holstein cows because the embryo bypasses the deleterious effects caused by milk production and heat stress during the first $7 \mathrm{~d}$ after insemination. Objectives of this study were to evaluate factors that may alter CR after AI or ET in lactating Holstein cows throughout $1 \mathrm{yr}$.

\section{MATERIALS AND METHODS}

\section{Location and Period}

The experiment was conducted from October 2003 to September 2004 at a commercial dairy farm located in Descalvado, São Paulo State, Brazil; latitude S $21^{\circ} 54^{\prime} 05^{\prime \prime}$, longitude W $47^{\circ} 37^{\prime} 26^{\prime \prime}$, and altitude $648 \mathrm{~m}$.

\section{Animals}

Multiparous lactating Holstein cows $(\mathrm{n}=1,025)$ at 55 to $547 \mathrm{DIM}$ and $33.1 \pm 7.2 \mathrm{~kg}$ of milk production per day were used for 12 mo from a herd consisting of 1,200 lactating cows. Animals were maintained in a free-stall barn with access to an adjoining sod-based area. Barns were cooled by intermittent sprinkling and forced ventilation to minimize the effects of heat stress. Cows were fed ad libitum with a TMR based on corn silage, fresh coast-cross grass (Cynodon dactylon), corn, cottonseed, soybean flour, minerals, and vitamins balanced to meet nutritional requirements for lactating dairy cows (NRC, 2001). Cows were milked 3 times a day in a side-byside milking system. Daily milk yield for each cow was recorded automatically.

\section{Reproductive Management, Al, and ET}

Nonpregnant cows with more than 55 DIM were evaluated monthly. When a corpus luteum (CL) was palpated per rectum, cows were treated with $\mathrm{PGF}_{2 \alpha}(500$ $\mu \mathrm{g}$ of cloprostenol, i.m.; Ciosin, Schering-Plough, Cotia, SP, Brazil), blocked by DIM and number of previous $\mathrm{AI}$, and randomly assigned to receive AI or ET (Figure 1). Estrus was detected by visual observation twice daily. Cows that were standing to be mounted by other females were considered in estrus. Cows that showed estrus 48 to $96 \mathrm{~h}$ after $\mathrm{PGF}_{2 \alpha}$ injection received $\mathrm{AI} 12$ $\mathrm{h}$ after detected estrus (AI group) or 1 embryo 6, 7, or $8 \mathrm{~d}$ after detected estrus (ET group).

Artificial insemination was performed by a single experienced technician $12 \mathrm{~h}$ after estrus detection. Semen from 4 sires was used. On d 7, the AI cows were evaluated by ultrasound (Aloka SSD, $500 \mathrm{~V}$ equipped with a $5-\mathrm{MHz}$ linear transrectal probe; Aloka Co. Ltd., Tokyo, Japan) to determine the presence of a CL.

Nonlactating Holstein cows served as embryo donors ( $\mathrm{n}=10$ ). Donors received a P4-releasing intravaginal device (CIDR; 1.9 g P4; Pfizer, Paulina, SP, Brazil) and $2 \mathrm{mg}$, i.m., of estradiol benzoate $1 \mathrm{mg} / \mathrm{mL}$; Index, Sao Paulo, SP, Brazil) on d -8 ( 8 d before AI). Superstimulatory treatments were initiated on $\mathrm{d}-4$, with decreasing doses of FSH (Pluset, Calier, Brazil) given twice daily, i.m., over $4 \mathrm{~d}$, totaling $350 \mathrm{IU}$. Donors received $\mathrm{PGF}_{2 \alpha}$ treatment on the morning of $\mathrm{d}-2$ and the $\mathrm{P} 4$ devices were removed on the morning of $d-1$. Donors also received $200 \mu \mathrm{g}$ of GnRH i.m. (Fertagyl, Intervet, Sao Paulo, SP, Brazil) on the morning of $d 0$ and were inseminated without estrus detection 12 and $24 \mathrm{~h}$ later. Semen from 4 sires was used (same sires as the AI group). Collection of ova or embryos was performed nonsurgically on d 7. Embryos were evaluated under a stereomicroscope and placed in TQC holding solution (Nutricell, Campinas, SP, Brazil) and maintained at ambient tem- 


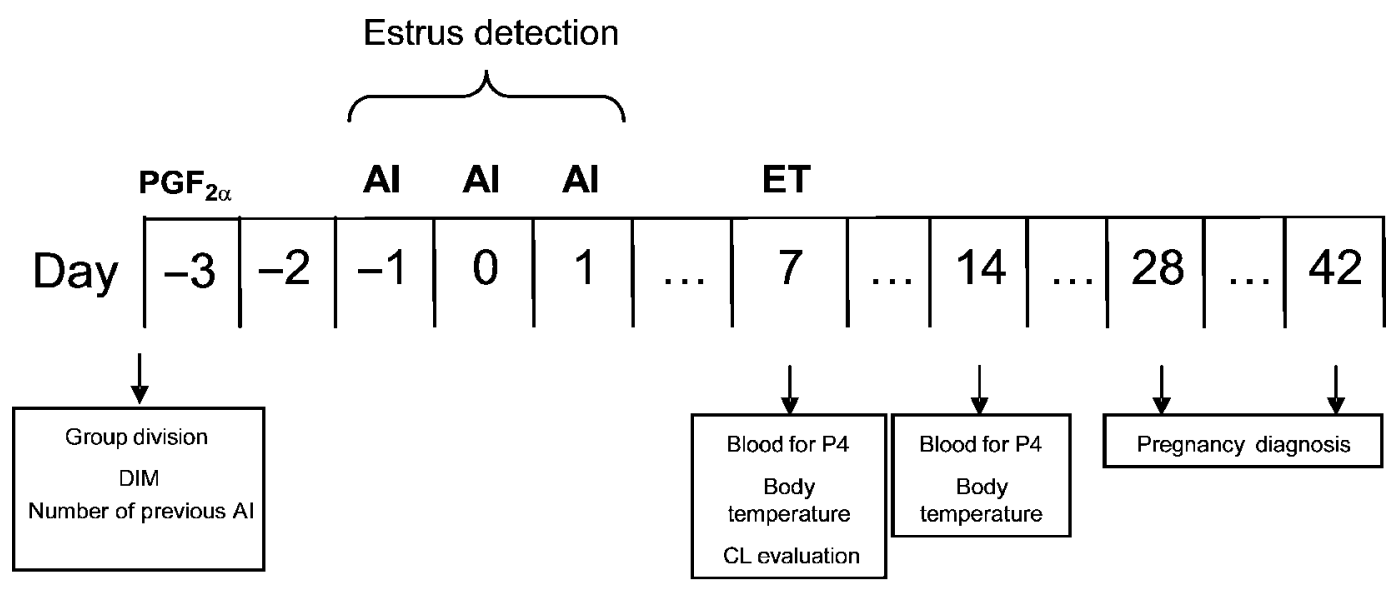

Figure 1. Chronology of the experiment. Nonpregnant cows with more than 55 DIM were evaluated monthly. When a corpus luteum (CL) was palpated per rectum, cows were treated with $\mathrm{PGF}_{2 \alpha}$, blocked by DIM and number of previous AI, and randomly assigned to receive $\mathrm{AI}$ or embryo transfer (ET). Estrus was detected by visual observation twice daily. Cows that showed estrus 48 to 96 h after PGF injection $_{2}$ received AI $12 \mathrm{~h}$ after detected estrus (AI group) or 1 embryo 6, 7, or $8 \mathrm{~d}$ after detected estrus (ET group). Pregnancy diagnosis was performed by ultrasonography on d 28 (27 to $29 \mathrm{~d}$ ) and 42 (41 to $43 \mathrm{~d}$ ). The DIM and number of previous AI were collected to verify their influence on conception rates. Milk production was measured from $7 \mathrm{~d}$ before $\mathrm{PGF}_{2 \alpha}$ injection until $\mathrm{d} 21$ and the average daily production from this period was considered. Rectal body temperature was recorded on d 7 and 14. Blood samples were collected on d 7 and 14 and analyzed for serum concentration of progesterone (P4).

perature. One excellent (grade 1) or good (grade 2) morula (stage 4), early blastocyst (stage 5), midblastocyst (stage 6), or expanded blastocyst (stage 7) was designated for fresh transfer using the International Embryo Transfer Society guideline for grading embryos (Wright, 1998).

Embryo transfer was performed by an experienced veterinarian on $\mathrm{d} 7 \mathrm{in}$ recipients that were 6,7 , or $8 \mathrm{~d}$ after estrus. Recipients were evaluated by ultrasound to determine the presence of CL before transfer. Cows without CL did not receive an embryo. One embryo was transferred nonsurgically to the uterine horn ipisilateral to the CL after epidural anesthesia.

\section{Pregnancy Diagnosis and Embryonic Loss}

Pregnancy diagnosis was performed by ultrasonography on d 28 ( 27 to $29 \mathrm{~d}$ ) and 42 (41 to $43 \mathrm{~d}$ ); embryonic loss was considered to have occurred when a cow was pregnant on d 28 but not pregnant on d 42 .

\section{Data and Samples}

Dates of estrus were divided into 4 seasons: spring (September, October, and November), summer (December, January, and February), fall (March, April, and May), and winter (June, July, and August). Days in milk and number of previous AI were collected to verify their influence on CR. Ovulation rate was calculated by dividing the number of cows from the AI or ET group with CL present on $d 7$ by the total number of cows that were detected in estrus 48 to $96 \mathrm{~h}$ after $\mathrm{PGF}_{2 \alpha}$ injection. Milk production was measured from $7 \mathrm{~d}$ before $\mathrm{PGF}_{2 \alpha}$ injection until $\mathrm{d} 21$ and the average daily production from this period was considered. Rectal body temperature was recorded on $\mathrm{d} 7$ and 14 . All embryos were collected and transferred on d 7, and ET cows received an embryo 6, 7, or $8 \mathrm{~d}$ after estrus. Blood samples were collected by coccygeal venipuncture on $d 7$ and 14 and analyzed for serum concentration of $\mathrm{P} 4$. Tubes were placed in ice immediately after blood collection and centrifuged $12 \mathrm{~h}$ later $(1,500 \times \mathrm{g}, 15 \mathrm{~min}$.). Samples were stored at $-20^{\circ} \mathrm{C}$ until analysis of $\mathrm{P} 4$ by RIA (Coat-a-Count, Diagnostic Products Corporation, Los Angeles, CA). The intraassay coefficients of variation were $4.2,6.0,4.8$, and $3.8 \%$ and the interassay coefficient of variation was $7.9 \%$. The assay sensitivity was $0.01 \mathrm{ng} / \mathrm{mL}$.

\section{Statistical Analysis}

The response variables ovulation, conception (d 28 and 42), and embryonic loss are binary variables that were denoted by 0 and 1 . A Bernoulli regression model was used in their analysis (Demétrio, 2001). Assuming that $Y_{i} \sim \operatorname{Bernoulli}\left(\pi_{i}\right)$, where $\pi_{i}$ is the success probability (probability of ovulation, conception, or embryonic loss) and $P\left(Y_{i}=y_{i}\right)=\pi_{i}^{y_{i}}\left(1-\pi_{i}\right)^{1-y_{i}}, y_{i}=0.1$, the GLM allowed the modeling of the expected proportions $\pi_{i}$ in terms of explanatory variables $\mathbf{x}_{i}$ (effects of treatments and covariates) through $\eta_{i}=\mathrm{g}\left(\pi_{i}\right)=\mathbf{x}_{i}^{\prime} \beta$, where $g\left(\pi_{i}\right)=$ $\log \left[\pi_{i} /\left(1-\pi_{i}\right)\right]$ is the logistic link function and $\boldsymbol{\beta}$ is a 
vector of $p$ unknown parameters. The success probability was estimated by $\hat{\pi}_{i}=\frac{\exp \left(\hat{\eta}_{i}\right)}{1+\exp \left(\hat{\eta}_{i}\right)}$.

The covariates used were treatment (AI or ET), season, DIM, number of previous AI, milk production, BT (d 7 and 14), P4 (d 7 and 14), sire, embryo quality (grade 1 or 2$)$, embryonic stage $(4,5,6$, or 7$)$, synchrony $(+1$, 0 , or -1 ), and all 2 -way interactions. For the continuous covariates, linear and quadratic effects were considered. A high correlation was found between DIM and the number of previous AI. This caused multicollinearity and only DIM remained in the model.

The selection of covariates was made by comparing the deviance to $\chi_{\nu, a}^{2}$ with $\nu$ degrees of freedom at $\alpha=$ 0.05 significance level. The models were fitted using the R software (www.r-project.org; Venables and Ripley, 2002).

Four different analyses were performed. The first analysis included all cows that were detected in estrus (ovulated or not). The second analysis included only cows with CL on $\mathrm{d} 7$ (ovulated cows). The third analysis included only ovulated cows that were $7 \mathrm{~d}$ after estrus to analyze the influence of $\mathrm{P} 4$ concentration on CR. The fourth analysis included all pregnant cows on $\mathrm{d} 28$, to evaluate factors affecting embryonic loss. Table 1 shows descriptive statistics of the 4 analyses.

\section{RESULTS AND DISCUSSION}

\section{Estrus Detection}

A total of 1,025 cows with a CL received an injection of $\mathrm{PGF}_{2 \alpha}$, and $37.8 \%$ (387/1025) were detected in estrus; $25 \%(96 / 387)$ on $d+1,57 \%(221 / 387)$ on $d 0$, and $18 \%$ on $d-1$ (70/387). Estrus detection rates $<50 \%$ are commonly observed in dairy herds (Washburn et al., 2002). Lopez et al. (2004) observed a decrease in the duration of estrus for cows that produced more than $39.5 \mathrm{~kg}$ of milk per day, which was associated with a reduction of circulating estradiol. The evaluation of the CL was done by rectal palpation and not all CL were responsive to $\mathrm{PGF}_{2 \alpha}$ (Momont and Seguin, 1984).

\section{First Analysis: All Cows That Were Detected in Estrus}

The analysis of all cows that were detected in estrus was done to compare our results with those of commercial dairy herds that use ET. Typically, the CR of inseminated cows (all cows that were detected in estrus) is compared with the CR of cows that received ET (ovulated cows). A comparison between all cows that were detected in estrus in both groups was performed (cows without CL did not receive embryos and were consid-

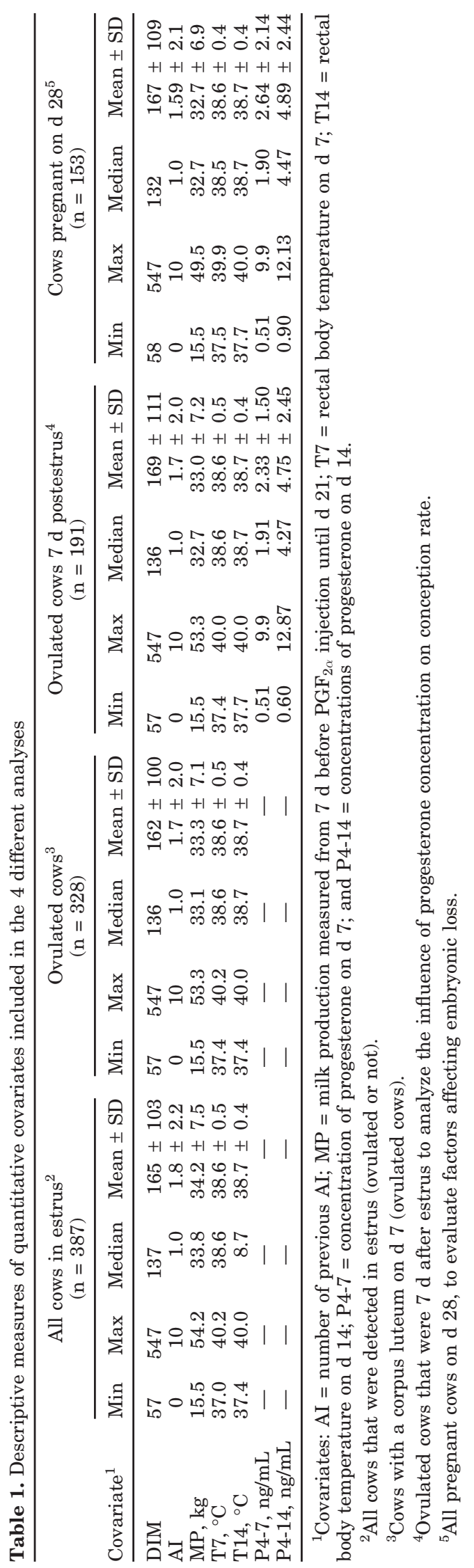


ered not pregnant). Of the 387 cows that were detected in estrus, $39.5 \%$ (153/387) were pregnant on $\mathrm{d} 28,32.6 \%$ (74/227) from $\mathrm{AI}$ and $49.4 \%$ (79/160) from ET. For the model for which the response variable was the probability of conception on $\mathrm{d} 28$, the covariates considered were season, treatment, DIM, milk production, BT (d 7 and 14), sire, and interactions. By fitting the logistic model to the data it was possible to detect the effect of treatment $(P<0.01)$ and the interaction between DIM and BT on d $7(P=0.03)$ but there was not effect of season or milk production. The probabilities of conception for both treatments as a function of BT (d 7) and DIM can be estimated by the equations:

$$
\begin{gathered}
\text { Probability of conception AI }= \\
\frac{\exp (-20.33+0.51 \mathrm{BT}+0.20 \mathrm{DIM}-0.01 \mathrm{BT} . \mathrm{DIM})}{1+\exp (-20.33+0.51 \mathrm{BT}+0.20 \mathrm{DIM}-0.01 \mathrm{BT} . \mathrm{DIM})}
\end{gathered}
$$

and

$$
\begin{gathered}
\text { Probability of conception ET }= \\
\frac{\exp (-19.56+0.51 \mathrm{BT}+0.20 \mathrm{DIM}-0.01 \mathrm{BT} . \mathrm{DIM})}{1+\exp (-19.56+0.51 \mathrm{BT}+0.20 \mathrm{DIM}-0.01 \mathrm{BT} . \mathrm{DIM})}
\end{gathered}
$$

When BT increased there was a reduction in the probability of conception (d 28), especially when DIM was greater. Chebel et al. (2004) also observed that CR is lower in cows with greater DIM.

Of the 387 cows that were detected in estrus, $33.1 \%$ (128/387) were pregnant on $\mathrm{d} 42,29.1 \%$ (66/227) from $\mathrm{AI}$ and $38.8 \%$ (62/160) from ET. For the model in which the response variable was the probability of conception on $\mathrm{d} 42$, the only covariate maintained was treatment (to avoid the comparison between nonpregnant cows and cows that had embryonic loss after d 28). Fitting the logistic model to the data demonstrated an effect of treatment $(P=0.05)$. When cows that did not ovulate from the ET group were included, we observed greater CR for ET 28 and $42 \mathrm{~d}$ after estrus.

\section{Second Analysis: Ovulated Cows (Presence of CL on $d 7$ )}

The analysis of ovulated cows was performed as a more appropriate comparison of conception rates for AI and ET.

Ovulation Rate. Of the 387 cows that were detected in estrus, 84.8\% (328/387) had a CL on d 7, 85.9\% (195/ 227) from AI and $83.1 \%$ (133/160) from ET. For the model in which the response variable was the probability of ovulation, the covariates considered were season, DIM, milk production, and 2-way interactions. There was evidence of an effect of DIM $(P=0.05)$, and the probability of ovulation as a function of DIM was estimated by the equation

$$
\begin{aligned}
& \text { Probability of ovulation }= \\
& \frac{\exp (2.05+0.002 \mathrm{DIM})}{1+\exp (2.05+0.002 \mathrm{DIM})}
\end{aligned}
$$

When DIM increased, the probability of ovulation decreased. The probability of ovulation of a cow at 60 DIM was $87.4 \%$, whereas for a cow at 350 DIM the probability was $79.7 \%$. There are few reports demonstrating the factors that influence ovulation rate. Different stress factors can lead to ovulation failure. LopezGatius et al. (2005) did not detect any effect of milk production and number of previous AI on the probability of conception, but found that the chance of ovulation failure was 3.9 times greater in warm seasons than in cold seasons. The decrease in ovulation rate in cows with greater DIM can be one of the reasons why some cows become repeat-breeders, thus continuous conception failure could be caused by ovulation failures. One of the greatest advantages of ET compared with $\mathrm{AI}$ is the opportunity to determine ovulation before ET, by assessing the presence of a CL. The evaluation of ovulation increases the probability of CR because cows with ovulation failure are not included.

Probability of $\boldsymbol{C R}$ on $\boldsymbol{d} 28$. To evaluate the effects of synchrony, embryo stage, embryo quality, and 2-way interactions on the probability of conception, only ovulating cows from the ET group were used. There was no effect of these factors on the probability of conception, and this is likely because only fresh embryos of grade 1 and 2 quality were transferred.

Of the 387 cows that were detected in estrus, $84.8 \%$ (328/387) ovulated. Of the 328 cows that ovulated, $46.6 \%(153 / 328)$ were pregnant on $d 28,37.9 \%(74 / 195)$ from AI and 59.4\% (79/133) from ET $(P<0.01)$. For the model in which the response variable was the probability of conception on $d 28$, the covariates considered were season, treatment, DIM, milk production, BT (d 7 and 14), sire, and 2-way interactions. Fitting the logistic model to the data demonstrated the effect of treatment $(P<0.01)$ and the quadratic effect of BT at d $7(P=0.02)$. The probabilities of conception for both treatments as a function of $\mathrm{BT}(\mathrm{d} 7)$ can be estimated by the equations

$$
\begin{gathered}
\text { Probability of conception AI }= \\
\frac{\exp \left(-1095.35+57.08 \mathrm{BT}-0.74 \mathrm{BT}^{2}\right)}{1+\exp \left(-1095.35+57.08 \mathrm{BT}-0.74 \mathrm{BT}^{2}\right)}
\end{gathered}
$$

and 
Table 2. Conception rates (CR) at d 28 and 42 in cows that were detected in estrus and in ovulated cows ${ }^{1}$

\begin{tabular}{|c|c|c|c|c|}
\hline \multirow[b]{2}{*}{ Group } & \multicolumn{2}{|c|}{ Cows detected in estrus } & \multicolumn{2}{|c|}{ Ovulated cows } \\
\hline & $\mathrm{CR} d 28, \%$ & $\mathrm{CR} \mathrm{d} 42, \%$ & $\mathrm{CR} d 28, \%$ & $\mathrm{CR} d 42, \%$ \\
\hline AI & $32.6(74 / 227)^{2}$ & $29.1(66 / 227)$ & $37.9(74 / 195)$ & $33.8(66 / 195)$ \\
\hline Embryo transfer & $49.4(79 / 160)$ & $38.8(62 / 160)$ & $59.4(79 / 133)^{2}$ & $46.6(62 / 133)$ \\
\hline$P$-value & 0.01 & 0.05 & 0.01 & 0.02 \\
\hline
\end{tabular}

${ }^{1}$ The analysis of cows detected in estrus and ovulated cows were performed as a more appropriate comparison of CR for AI and embryo transfer.

${ }^{2}$ Typically, the CR of inseminated cows (all cows that were detected in estrus) is compared with the CR of cows that received embryo transfer (ovulated cows).

$$
\begin{gathered}
\text { Probability of conception ET }= \\
\frac{\exp \left(-1094.44+57.08 \mathrm{BT}-0.74 \mathrm{BT}^{2}\right)}{1+\exp \left(-1094.44+57.08 \mathrm{BT}-0.74 \mathrm{BT}^{2}\right)} .
\end{gathered}
$$

High BT on $\mathrm{d} 7$ decreased the probability of conception determined on $\mathrm{d} 28$. The BT on d 14 did not influence conception determined on $\mathrm{d} 28$. These data indicated that the effect of BT on the probability of conception occurred before $\mathrm{d} 14$. Other data indicated that periods from ovulation to the third day of embryonic development are very susceptible to heat stress. Elevated temperatures reduce the proportion of embryos that continue to develop (Ealy et al., 1993). The effects of heat stress decrease as embryos become more developed because they acquire resistance to the negative effects of heat stress as they mature (Ealy et al., 1993; Hansen and Arechiga, 1999). Our data indicate that perhaps heat stress continues to have a negative influence after the third day, but not as long as d 14. The high BT had a negative influence on $\mathrm{AI}$ and $\mathrm{ET}$ in the same way, but CR of ET remained greater than AI.

Probability of $\boldsymbol{C R}$ on $\boldsymbol{d} 42$. Of the 328 cows that ovulated, 39.0\% (128/328) were pregnant on $\mathrm{d} 42,33.8 \%$ $(66 / 195)$ from AI and $46.6 \%(62 / 133)$ from $\operatorname{ET}(P<0.02)$. There was evidence of the effect of treatment on pregnancy $(P=0.02)$. Table 2 compares $\mathrm{CR}$ of the different analyses that were performed. The data presented demonstrated that fresh embryos increased CR of lactating Holstein cows compared with AI. High BT had a negative effect on the CR of AI and ET.

\section{Third Analysis: Ovulating Cows That Were 7 d After Estrus}

The analysis of ovulating cows that were $7 \mathrm{~d}$ after estrus was done to avoid differences of P4 concentrations because of the differences in the age of the CL for the AI and ET groups. In this analysis, the embryo age was $7 \mathrm{~d}$ and the recipient was $7 \mathrm{~d}$ after detected estrus. Table 3 shows the serum concentrations of P4 among different synchronies for the $\mathrm{AI}$ and ET groups. Of the
191 ovulating cows that were detected in estrus on $d$ $0,49.2 \%(94 / 191)$ were pregnant on d 28, 37.5\% (39/ 104) from AI and $63.2 \%(55 / 87 ; P<0.01)$ from ET. On $d 42,40.8 \%$ (78/191) were pregnant, $31.7 \%$ (33/104) from AI and 51.7\% (45/87; $P<0.01)$ from ET. For the model in which the response variable was the probability of conception on $\mathrm{d} 28$, the covariates considered were season, treatment, DIM, milk production, BT (d 7 and 14), P4 (d 7 and 14), sire, and 2-way interactions. Fitting the logistic model demonstrated evidence for the effects of $\mathrm{P} 4$ concentration on $\mathrm{d} 7(P=0.03)$, a tendency of a quadratic effect of BT at d $7(P=0.09)$, and an effect of milk production $(P=0.04)$ on the AI group. For the ET group there was only a tendency of the quadratic effect of BT at d $7(P=0.08)$. The probabilities of conception for both treatments as a function of $\mathrm{P} 4$ concentration (d 7), BT (d 7), and milk production can be estimated by the equations

Probability of conception AI =

$\frac{\exp \left(-1507+0.36 . \mathrm{P} 4+78.6 \mathrm{BT}-1.02 \mathrm{BT}^{2}-0.07 \mathrm{Milk}\right)}{1+\exp \left(-1507+0.36 . \mathrm{P} 4+78.6 \mathrm{BT}-1.02 \mathrm{BT}^{2}-0.07 \mathrm{Milk}\right)}$

and

$$
\begin{gathered}
\text { Probability of conception ET }= \\
\frac{\exp \left(-1507+78.6 \mathrm{BT}-1.02 \mathrm{BT}^{2}\right)}{1+\exp \left(-1507+78.6 \mathrm{BT}-1.02 \mathrm{BT}^{2}\right)} .
\end{gathered}
$$

The adjusted curves are shown in Figures 2, 3 and 4 . For the AI group, greater P4 concentration on $d 7$ was associated with greater probability of conception (d 28). This was not observed in the ET group (Figure 2). Concentrations of P4 (d 14) did not influence the probability of conception in either group. These data indicate that greater concentrations of $\mathrm{P} 4$ had a positive effect in the first days of embryonic development (before d 14). Sartori et al. (2006) observed lower CR for AI than ET in cows that ovulated a smaller follicle $(\leq 15 \mathrm{~mm})$, but not average (16 to $19 \mathrm{~mm})$ or larger $(\geq 20 \mathrm{~mm})$ follicles. 

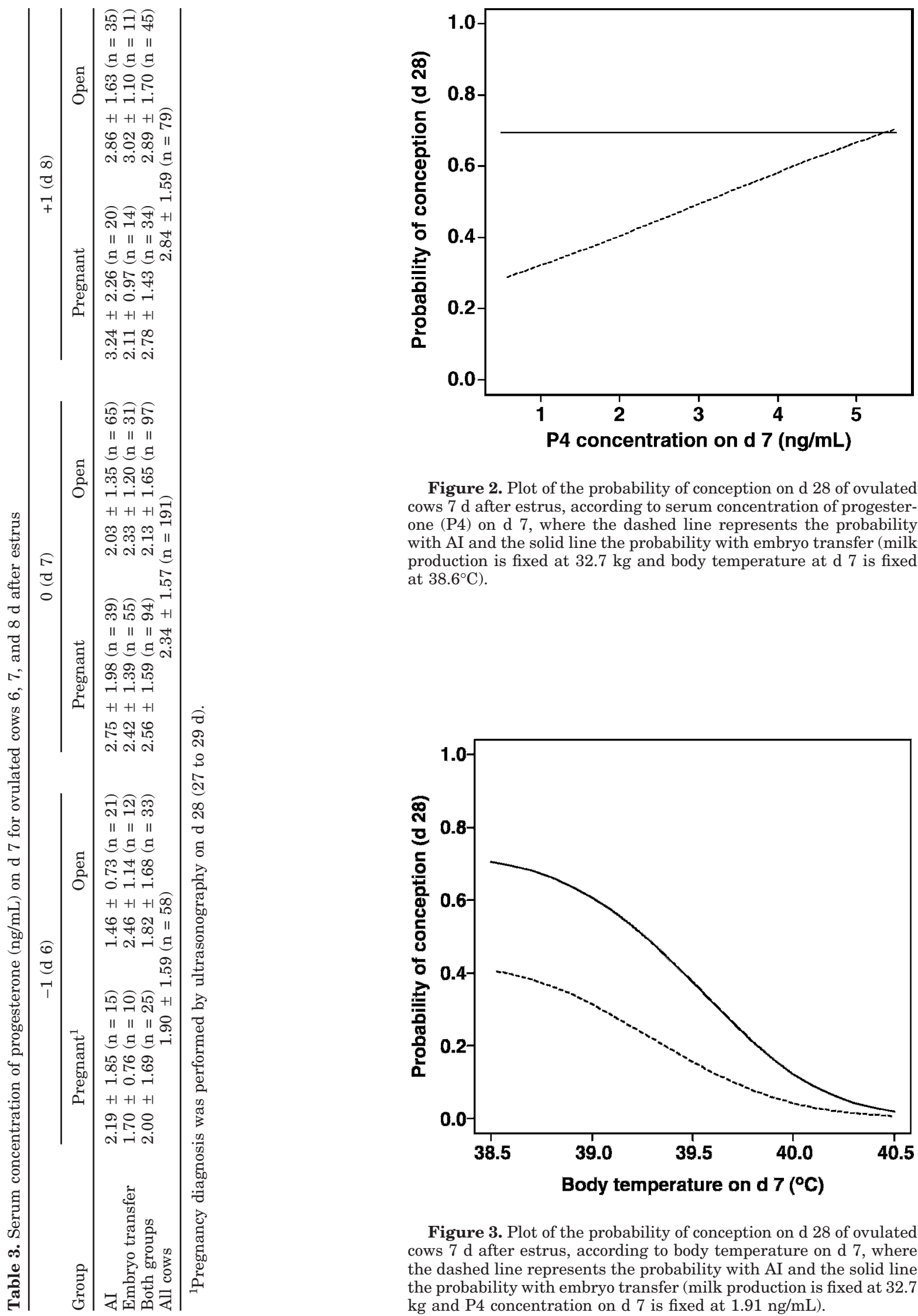

Figure 2. Plot of the probability of conception on d 28 of ovulated cows $7 \mathrm{~d}$ after estrus, according to serum concentration of progesterone (P4) on $\mathrm{d} 7$, where the dashed line represents the probability with AI and the solid line the probability with embryo transfer (milk production is fixed at $32.7 \mathrm{~kg}$ and body temperature at $\mathrm{d} 7$ is fixed at $38.6^{\circ} \mathrm{C}$.

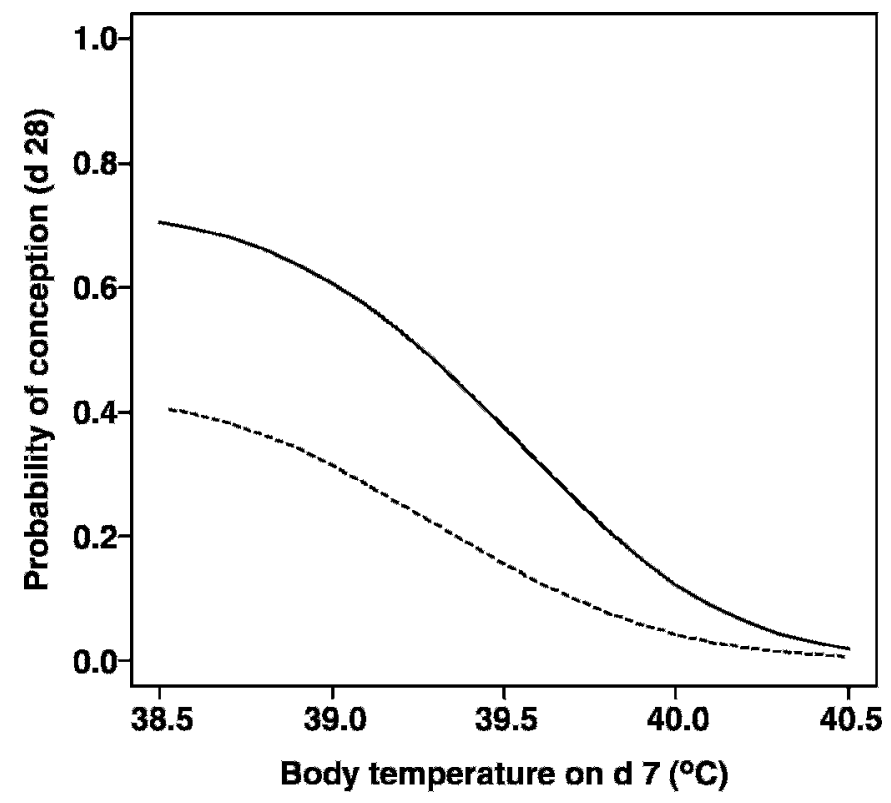

Figure 3. Plot of the probability of conception on d 28 of ovulated cows $7 \mathrm{~d}$ after estrus, according to body temperature on $\mathrm{d} 7$, where the dashed line represents the probability with AI and the solid line the probability with embryo transfer (milk production is fixed at 32.7 $\mathrm{kg}$ and $\mathrm{P} 4$ concentration on $\mathrm{d} 7$ is fixed at $1.91 \mathrm{ng} / \mathrm{mL}$ ). 


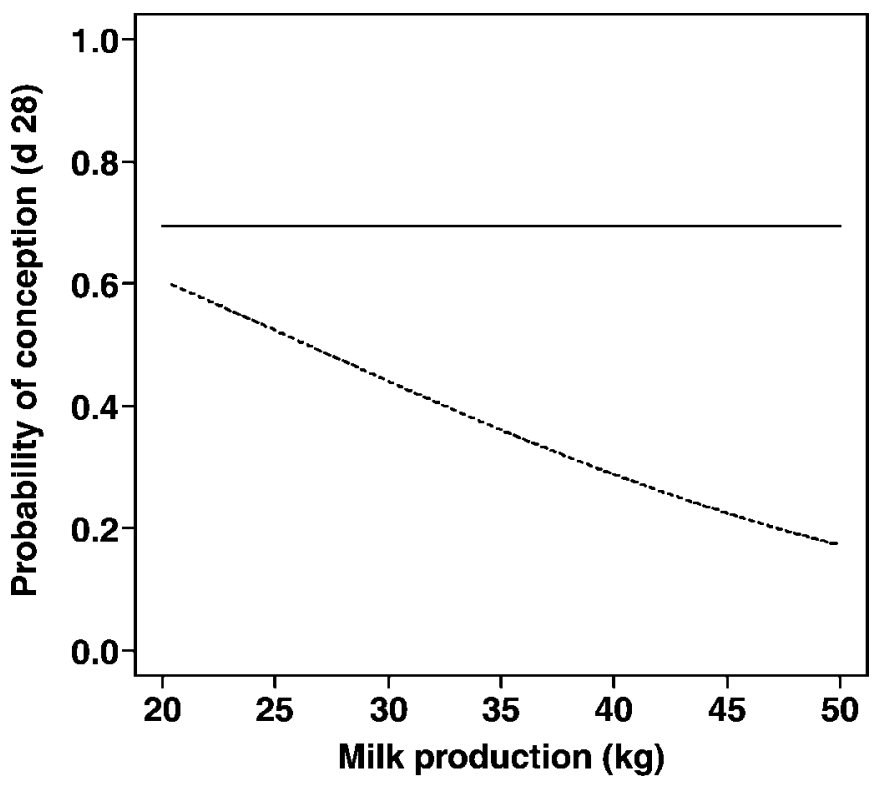

Figure 4. Plot of the probability of conception on d 28 of ovulated cows $7 \mathrm{~d}$ after estrus, according to milk production, where the dashed line represents the probability with $\mathrm{AI}$ and the solid line the probability with embryo transfer (body temperature at $\mathrm{d} 7$ is fixed at $38.6^{\circ} \mathrm{C}$ and progesterone concentration on $\mathrm{d} 7$ is fixed at $1.91 \mathrm{ng} / \mathrm{mL}$ ). Milk production was measured from $7 \mathrm{~d}$ before $\mathrm{PGF}_{2 \alpha}$ injection until $\mathrm{d} 21$ and the average daily production from this period was considered.

Serum concentrations of P4 of synchronized cows were lower in cows ovulating smaller follicles compared with average or larger diameter follicles on $\mathrm{d} 7$ in both $\mathrm{AI}$ and ET cows. Lower concentrations of P4 after AI may reduce the embryonic development and survival rate (Mann and Lamming, 2001; Green et al., 2005). Progesterone controls the uterine environment and influences embryonic development (Mann and Lamming, 2001; Green et al., 2005; Mann et al., 2006). Green et al. (2005) showed that $\mathrm{P} 4$ also changes the oviductal environment and acts indirectly on initial embryo development. When Mann et al. (2006) studied P4 supplementation; they observed that the insertion of an intravaginal P4containing device between $\mathrm{d} 5$ and 9 of the cycle caused an increase in embryo length $16 \mathrm{~d}$ after AI. The P4 supplementation between $\mathrm{d} 12$ and 16 did not increase the length of the embryo. The results from this study confirm the importance of $\mathrm{P} 4$ on the embryonic development before $d$ 14. Cows from the ET group were not influenced by concentrations of $\mathrm{P} 4$, probably because they received an embryo that was already developed (grade 1 or 2). These findings are valuable in understanding the mechanisms involved on lower conception rates of lactating dairy cows. Dairy cows consume highdensity diets, have high hepatic blood flow, and high rates of P4 metabolism (Sangsritavong et al., 2002), and consequently low blood concentrations of P4. The low P4 is probably related to the reduced fertility of dairy cows (Lucy 2001; Washburn et al., 2002).

We observed that elevated BT on $\mathrm{d} 7$ reduced the probability of conception ( $28 \mathrm{~d}$ ) on AI and ET (Figure 3 ). The BT on d 14 did not influence this. Heat stress may retard embryonic development or cause failure of embryonic development before d 14 (Ryan et al., 1993).

An increase in milk production negatively affected the probability of conception ( $28 \mathrm{~d}$ ) after AI but not after ET, indicating that milk production had a negative impact before $\mathrm{d}$ 7, perhaps through its effects on follicular development, fertilization, or initial embryo development. As milk production increased, ET became more important to bypass the negative effects on the probability of conception (Figure 4). Sartori et al. (2002) demonstrated that embryos that were produced in lactating cows had lower quality than those produced in nonlactating cows or heifers.

Greater CR can be achieved with the use of ET because the effects of the concentrations of $\mathrm{P} 4$ and milk production can be bypassed when a 7-d-old embryo is used. This information allows us to conclude that the ET of good-quality, fresh embryos can be used as a tool to increase $\mathrm{CR}$ in high-producing dairy cows.

\section{Fourth Analysis: Embryonic Loss}

Of the 153 cows that were pregnant on $d 28,16.3 \%$ (25/153) were not pregnant on d 42,10.8\% (8/74) from $\mathrm{AI}$ and $21.5 \%$ (17/79) from ET. For the model in which the response variable was the probability of embryonic loss, the covariates considered were season, treatment, DIM, milk production, BT (d 7 and 14), and 2-way interactions. Fitting the logistic model to the data detected a tendency for the effect of BT at d $7(P=0.10)$ and treatment $(P=0.06)$. The probabilities of embryonic loss for both treatments as a function of BT (d 7) can be estimated by the equations:

$$
\begin{aligned}
& \text { Probability of embryonic loss } \mathrm{AI}= \\
& \frac{\exp (-36.23+0.88 \mathrm{BT})}{1+\exp (-36.23+0.88 \mathrm{BT})}
\end{aligned}
$$

and

$$
\begin{aligned}
& \text { Probability of embryonic loss ET }= \\
& \frac{\exp (-35.41+0.88 \mathrm{BT})}{1+\exp (-35.41+0.88 \mathrm{BT})}
\end{aligned}
$$

The adjusted curves are shown in Figure 5. We verified that an increase of BT (d 7) promoted a high probability of embryonic loss, but BT on d 14 did not have an effect. This result indicates that there are residual 


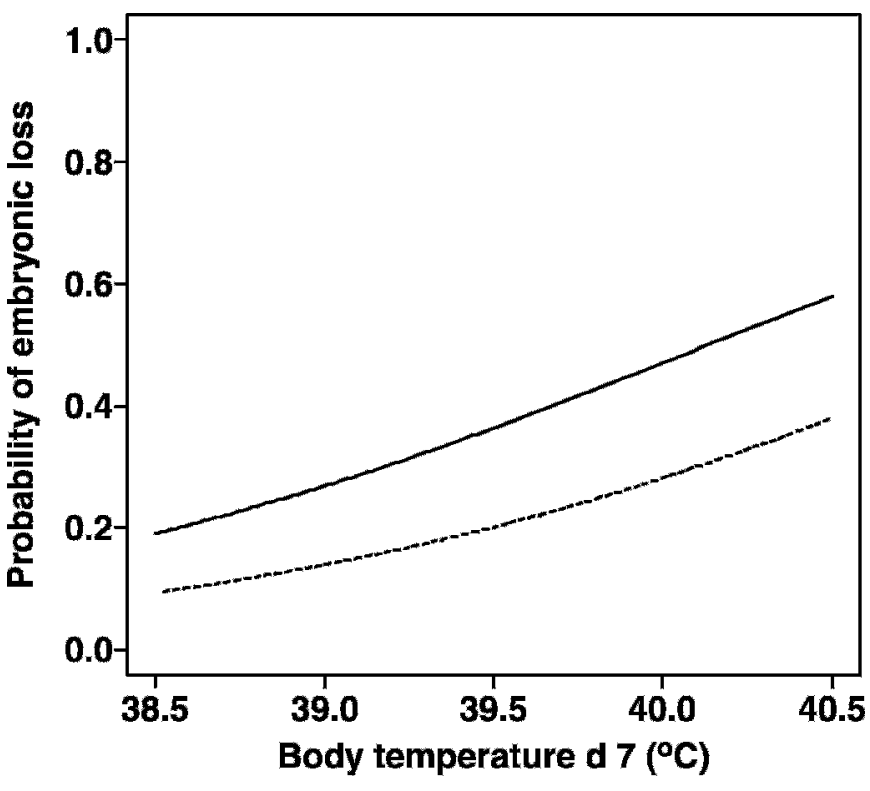

Figure 5. Plot of the probability of embryonic loss according to body temperature on $\mathrm{d} 7$, where the dashed line represents the probability with AI and the solid line the probability with embryo transfer. Embryonic loss was considered to have occurred when a cow was pregnant on d 28 but not pregnant on d 42 .

effects of high BT on initial embryo development. Factors affecting embryonic loss are still not well explained (Chebel et al., 2004). Embryonic loss is a variable that is hard to study because there are many factors involved. More than $70 \%$ of embryonic losses are caused by noninfectious causes, and those are generally multifactorial and hard to diagnose (Christianson, 1992; Vanroose et al., 2000). The embryonic loss rate in lactating cows varies from 10 to $60.5 \%$ (Vasconcelos et al., 1997; Chebel et al., 2004; Sartori, 2004; Sartori et al., 2006). Sartori et al. (2006) did not find any significant difference in embryonic loss between AI (18.6\%) and ET (26.2\%). Besides the influence of temperature, other causes of embryonic loss in the ET group remain undefined by this study.

\section{CONCLUSIONS}

The transfer of fresh embryos is an important tool to increase the probability of conception in lactating Holstein cows because it can bypass the negative effects of high milk production and low concentrations of P4 on the early embryo. The superiority of ET over AI is more evident in high-producing cows. High BT measured on $\mathrm{d} 7$ has a negative effect on CR and embryonic loss.

\section{ACKNOWLEDGMENTS}

This research was supported by Agrindus SA and Samvet Embrioes (Descalvado, SP, Brazil).

\section{REFERENCES}

Bergfeld, E. G., F. N. Kojima, A. S. Cupp, M. E. Wehrman, K. E. Peters, V. Mariscal, T. Sanchez, and J. E. Kinder. 1996. Changing dose of progesterone results in sudden changes in frequency of luteinizing hormone pulses and secretion of $17 \beta$-estradiol in bovine females. Biol. Reprod. 54:546-553.

Chebel, R. C., J. E. P. Santos, J. P. Reynolds, R. L. A. Cerri, S. O. Juchem, and M. Overton. 2004. Factors affecting conception rate after artificial insemination and embryonic loss in lactating dairy cows. Anim. Reprod. Sci. 84:239-255.

Christianson, W. T. 1992. Stillbirths, mummies, abortions and early embryonic death. Vet. Clin. North Am. 8:623-639.

Demétrio, C. G. B. 2001. Modelos lineares generalizados. 46a Reunião anual da RBRAS ESALQ, Piracicaba, SP, Brazil.

Drost, M., J. D. Ambrose, M. J. Thatcher, C. K. Cantrell, K. E. Wolfsdorf, and J. F. Hasler. 1999. Conception rates after artificial insemination or embryo transfer in lactating dairy cows during summer in Florida. Theriogenology 52:1161-1167.

Ealy, A. D., M. Drost, and P. J. Hansen. 1993. Developmental changes in embryonic resistance to adverse effects of maternal heat stress in cows. J. Dairy Sci. 76:2899-2905.

Green, M. P., M. G. Hunter, and G. E. Mann. 2005. Relationships between maternal hormone secretion and embryo development on d 5 of pregnancy in dairy cows. Anim. Reprod. Sci. 88:179-189.

Hansen, P. J., and C. F. Arechiga. 1999. Strategies for managing reproduction in the heat-stressed dairy cow. J. Anim. Sci. 77:37-50.

Harrison, R. O., S. P. Ford, J. W. Young, A. J. Conley, and A. E. Freeman. 1990. Increased milk production versus reproductive and energy status of high producing dairy cows. J. Dairy Sci. 73:2749-2758.

Kadzere, C. T., M. R. Murphy, N. Silanikove, and E. Maltz. 2002. Heat stress in lactating dairy cows: A review. Livest. Prod. Sci. 77:59-91.

Lopez, H., L. D. Satter, and M. C. Wiltbank. 2004. Relationship between level of milk production and estrus behavior of lactating dairy cows. Anim. Reprod. Sci. 81:209-223.

Lopez-Gatius, F., M. Lopez Bejar, M. Fenech, and R. H. F. Hunter. 2005. Ovulation failure and double ovulation in dairy cattle: Risk factors and effects. Theriogenology 63:1298-1307.

Lucy, M. C. 2001. Reproductive loss in high-producing dairy cattle: Where will it end? J. Dairy Sci. 84:1277-1293.

Mann, G. E., M. D. Fray, and G. E. Lamming. 2006. Effects of time of progesterone supplementation on embryo development and interferon- $\tau$ production in the cow. Vet. J. 171:500-503.

Mann, G. E., and G. E. Lamming. 2001. Relationship between the maternal endocrine environment, early embryo development and inhibition of the luteolytic mechanism in the cow. Reproduction 121:175-180.

Momont, H. W., and B. E. Seguin. 1984. Influence of day of estrus cycle on response to $\mathrm{PGF}_{2 \alpha}$ products: Implications for AI programs for dairy cattle. 10th Proc. Int. Congr. Anim. Reprod., UrbanaChampaign, IL. Univ. Illinois, Urbana, IL.

National Research Council. 2001. Nutrient Requirements of Dairy Cattle. 7th rev. ed. Natl. Acad. Sci., Washington, DC.

Putney, D. J., M. Drost, and W. W. Thatcher. 1989. Influence of summer heat stress on pregnancy rates of lactating dairy cattle following embryo transfer or artificial insemination. Theriogenology 31:765-778.

Ryan, D. P., J. F. Prichard, E. Kopel, and R. A. Godke. 1993. Comparing early embryo mortality in dairy cows during hot and cool seasons of the year. Theriogenology 39:719-737.

Sangsritavong, S., D. K. Combs, R. Sartori, L. E. Armentano, and M. C. Wiltbank. 2002. High feed intake increases liver blood flow 
and metabolism of progesterone and estradiol- $17 \beta$ in dairy cattle. J. Dairy Sci. 85:2831-2842.

Sartori, R. 2004. Fertilização e morte embrionéria em bovinos. Acta Scientiae Veterinariae 32:35-50.

Sartori, R., A. Gumen, J. N. Guenther, A. H. Souza, D. Z. Caraviello, and M. C. Wiltbank. 2006. Comparison of artificial insemination versus embryo transfer in lactating dairy cows. Theriogenology 65:1311-1321.

Sartori, R., R. Sartor-Bergfelt, S. A. Mertens, J. N. Guenther, J. J. Parrish, and M. C. Wiltbank. 2002. Fertilization and early embryonic development in heifers and lactating cows in summer and lactating and dry cows in winter. J. Dairy Sci. 85:2803-2812.

Stock, A. E., and J. E. Fortune. 1993. Ovarian follicular dominance in cattle: Relationship between prolonged growth of the ovulatory follicle and endocrine parameters. Endocrinology 132:1108-1114.

Stronge, A. J. H., J. M. Sreenan, M. G. Diskin, J. F. Mee, D. A. Kenny, and D. G. Morris. 2005. Post-insemination milk progesterone concentration and embryo survival in dairy cows. Theriogenology 64:1212-1224.

Thatcher, W. W., A. Guzeloglu, R. Mattos, M. Binelli, T. R. Hansen, and J. K. Pru. 2001. Uterine-conceptus interactions and reproductive failure in cattle. Theriogenology 56:1435-1450.
Vanroose, G., A. Kruif, and A. Van Soom. 2000. Embryonic mortality and embryo-pathogen interactions. Anim. Reprod. Sci. 6061:131-143.

Vasconcelos, J. L. M., S. Sangsritavong, S. J. Tsai, and M. C. Wiltbank. 2003. Acute reduction in serum progesterone concentration after feed intake in dairy cows. Theriogenology 60:795-807.

Vasconcelos, J. L. M., R. W. Silcox, J. A. Lacerda, J. R. Pursley, and M. C. Wiltbank. 1997. Pregnancy rate, pregnancy loss, and response to heat stress after $\mathrm{AI}$ at 2 different times from ovulation in dairy cows. Biol. Reprod. 56(Suppl. 1):140. (Abstr.)

Vasconcelos, J. L. M., R. W. Silcox, G. J. M. Rosa, J. R. Pursley, and M. C. Wiltbank. 1999. Synchronization rate, size of the ovulatory follicle, and pregnancy rate after synchronization of ovulation beginning on different days of the estrus cycle in lactating dairy cows. Theriogenology 52:1067-1078.

Venables, W. N., and B. D. Ripley. 2002. Modern Applied Statistics with S. 4th ed. Springer-Verlag, New York, NY.

Washburn, S. P., W. J. Silvia, C. H. Brown, B. T. McDaniel, and A. J. McAllister. 2002. Trends in reproductive performance in southeastern Holstein and Jersey DHI herds. J. Dairy Sci. 85:244-251.

Wright, J. M. 1998. Photographic illustrations of embryo developmental stage and quality scores. Pages 167-170 in Manual of the International Embryo Transfer Society. 3rd ed. D. A. Stringfellow and S. M. Seidel, ed. IETS, Savoy, IL. 